RESEARCH PAPER

\title{
A randomised clinical trial of nicotine patches for treatment of spit tobacco addiction among adolescents
}

\author{
R C Stotts, P K Roberson, E Y Hanna, S K Jones, C K Smith
}

Tobacco Control 2003;12(Suppl IV):iv1 1-iv15

See end of article for authors' affiliations

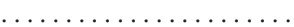

Correspondence to: Dr Craig Stotts, 817 Cobblestone Circle, North Little Rock, AR 72116, USA;

cstotts@utmem.edu
Background: This study tested the efficacy of nicotine patches in combination with behavioural therapy for the treatment of adolescent spit tobacco addiction. Prior interventions had resulted in mean cessation rates below $15 \%$ at one year.

Methods: This study, the PATCH Project, used a three group, placebo controlled, randomised clinical trial design. The control group received a standard 3-5 minute counselling followed by a two week follow up phone call. The two intervention groups received a six week behavioural intervention; in addition, one group received active nicotine patches while the other group received placebo patches. Both groups received quarterly stage based telephone counselling.

Results: At one year, the usual care group's spit tobacco cessation rate was $11.4 \%$ (exact $95 \%$ confidence interval (Cl) $6.1 \%$ to $19.1 \%$ ), placebo patch $25.0 \%(95 \% \mathrm{Cl} 16.9 \%$ to $34.7 \%)$, and the active patch $17.3 \%$ (95\% Cl $10.4 \%$ to $26.3 \%)$. When both patch groups were combined, the cessation rate was $21.2 \% 195 \% \mathrm{Cl}$ $15.7 \%$ to $27.6 \%$ ). The cessation rates for active and placebo patch were not significantly different (exact two sided $p=0.22$ ), while the combined patch groups had a significantly greater cessation rate than usual care (exact two sided $p=0.04$ ).

Conclusions: The behavioural intervention proved to be about twice as successful as previous interventions, but the nicotine patch offered no improvement in cessation rates. The behavioural intervention is based on publicly available materials and can be easily adapted for widespread use, particularly in high schools.
$\mathrm{T}$ he use of spit tobacco (snuff and chew tobacco) among adolescent males in the USA has become almost as popular as cigarettes in some sections of the country. Its use is most prevalent in the south and midwest areas, followed by the west and the northeast. ${ }^{1}$ There are approximately 7.6 million spit tobacco (ST) users in the USA. $^{2}$ Some users begin in first grade ${ }^{3}$ while most initiate regular usage in middle school or high school. ${ }^{4}$ More boys (14.2\%) are current users than girls (1.3\%), and whites are significantly more likely to use ST than other ethnic groups. ${ }^{1}$

ST usage is a known risk factor for oral diseases such as the pre-cancerous leukoplakia lesion, gingival recession, periodontal disease, and oral cancer. ${ }^{5-7}$ One study found that among professional baseball players who used at least four tins per week, $84 \%$ had leukoplakia. ${ }^{8}$ ST usage is also a known risk factor for cancer of the stomach, larynx, and oesophagus ${ }^{9}$ and for cardiovascular disease. ${ }^{10}$ Hatsukami and Severson ${ }^{11}$ thoroughly reviewed the ST problem.

ST use is a predictor of cigarette use and is considered a "gateway drug" to smoking. ${ }^{12}$ More than half of current ST users want to quit and have made at least one serious attempt. ${ }^{13}$ Prior ST cessation programmes for adolescent users have reported poor results, ranging from $0-13 \%$ success rates at six months. ${ }^{14-19}$ One study used a more intensive intervention in dentists' offices resulting in a 12 month cessation rate of $18 \%$; however, the majority of subjects were adults. ${ }^{18}$ Although at least one study used the nicotine patch with adolescent smokers, ${ }^{20}$ no studies before the present one had attempted to combine behavioural interventions with the nicotine patch for adolescent ST users. The only other ST cessation study that had used a pharmacological adjunct was one study that used nicotine gum with adult ST users, but the results were negative for periods longer than 10 weeks; this study indicated that group behavioural treatment was more effective than minimal intervention at six months. ${ }^{21}$

The purpose of this study was to determine the efficacy of a behavioural intervention designed specifically for ST cessation and whether nicotine patches would enhance cessation rates. Control groups included a usual care group and a group that received the behavioural intervention combined with a placebo patch.

\section{METHODS}

Subjects, screening, and randomisation

Eligible subjects were adolescent males aged 14-19 years who reported regular use of ST currently and for the previous year and who wanted to quit. Regular use was defined as using either snuff or chewing tobacco on at least five of seven days per week. If they were concurrent cigarette smokers, they also had to agree to quit smoking at the same time as ST cessation. Exclusion criteria were being female, unwillingness to be randomised, or unwillingness to quit all forms of tobacco use. No requirements or limitations were placed on subject enrolment based on the number of previous quit attempts, although this information was asked on the baseline questionnaire.

Subjects were recruited at 41 high schools throughout Arkansas. Radio ads and a website were used to increase awareness of the project before contacting each school. The principals at these schools gave permission for the PATCH project team to give a presentation in the school auditorium regarding the dangers of ST use and the research study we were conducting. The presentation involved a 15 minute audiovisual presentation and a 10 minute description of the research study. All students were invited to come forward for a free oral screening; those who stated they were ST users were invited to participate in the study. 


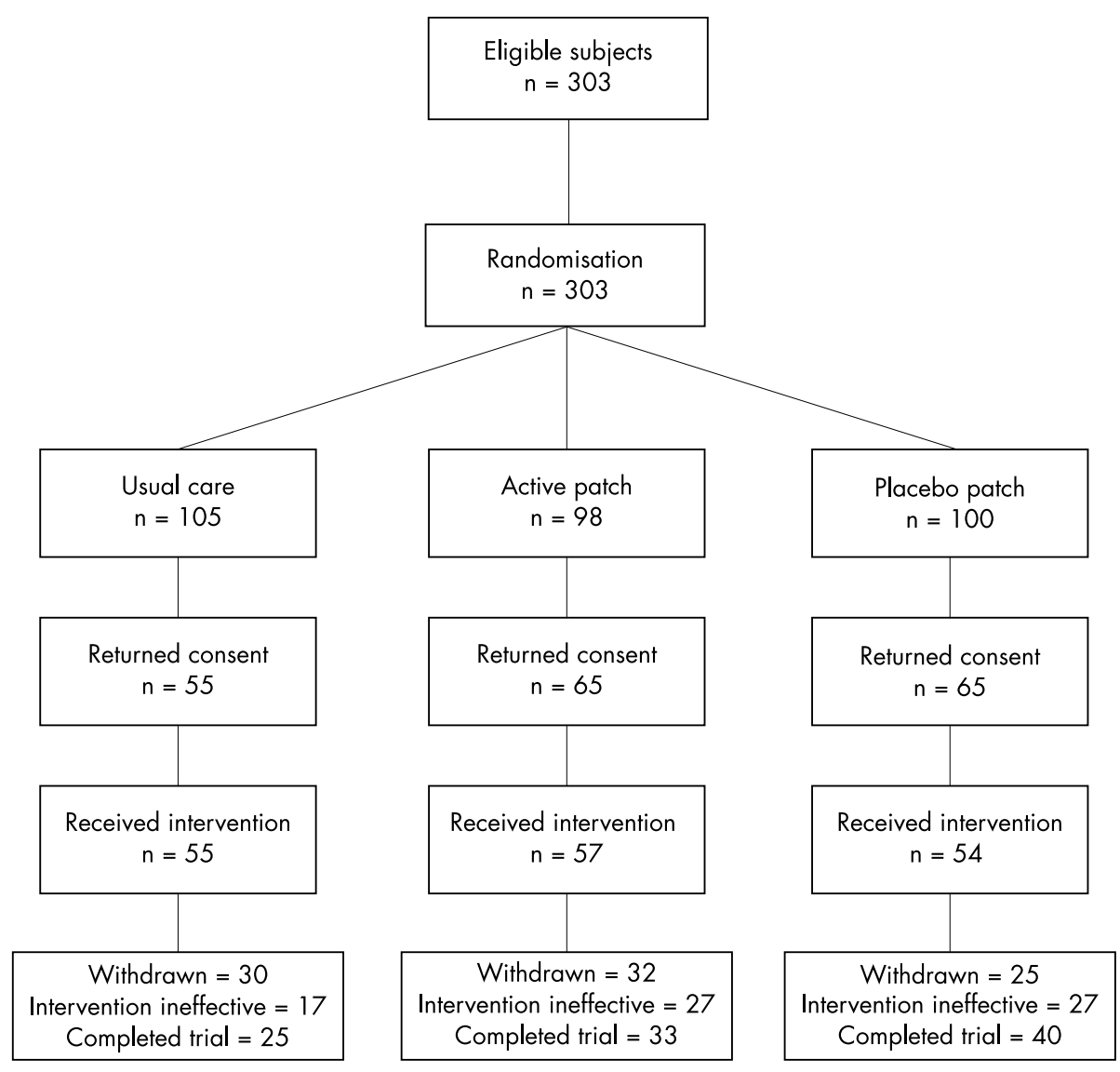

Figure 1 PATCH Project design.

A total of 303 subjects were enrolled and randomly assigned individually to one of three arms: active nicotine patch $(\mathrm{n}=98)$, placebo patch $(\mathrm{n}=101)$, and usual care $(\mathrm{n}=105)$ (fig 1$)$. The project statistician generated the randomisation scheme via the uniform random number generator in the SAS statistical software package; she never met with any of the subjects. The health educators were given a form that was used to write down the potential subject's name in order. Once the name was written down, the educator removed a sticker next to the name which then revealed whether the subject was in a "patch" group or the usual care group. Once the consent forms were returned and the subjects had attended at least three classes (the minimum number to be prepared adequately for the quit date), the pharmacist, who also never met any of the subjects, matched the subject's ID number (no names) with a more detailed randomisation list which indicated which group the "patch" group member was assigned to-that is, active or placebo. Further, the pharmacist was given saliva cotinine information that was used to determine the dosing schedule for active patches, as described below.

The codes for identifying subjects who were assigned to either the active or placebo patches were not broken until the study was completed. The codes were kept locked in the PI's office. Subject names were kept separately from their project ID numbers and in locked offices within the PATCH Project suite. The project statistician and pharmacist were only given ID numbers while the health educators only used names and had no access to the codes for active/placebo status of the subjects.

Subjects aged 14-17 years received a consent form for their parents to sign and an assent form for themselves. Subjects aged 18-19 years were given consent forms that did not require parental signatures. The study protocol and the consent form process were approved by the University of Arkansas for Medical Sciences institutional review board.

\section{Treatment}

Usual care subjects received a 5-10 minute counselling followed by a phone call two weeks later. No further interventions were provided. Phone calls at six months post-intervention were used for tracking purposes only. At one year, subjects were asked to complete a telephone interview to determine tobacco use status.

Both the active and placebo patch groups received six weeks of 50 minute behavioural intervention classes based on National Cancer Institute (NCI) educational materials. These materials were originally designed for adult baseball players, but class contents and learning activities were adjusted to be appropriate for the subjects' age group. A health educator met with them at a site on or near school property each week and provided pizza, soft drinks, and a \$5 gift certificate. Subjects in the active patch group were combined with placebo patch subjects for these classes; neither the subject nor the health educator knew their group assignment. Between weeks 3-4 the subjects selected a quit date and received a week's supply of patches; patch therapy continued for six weeks. Adverse side effects were evaluated by the project physician.

A toll-free number (1-888-QUIT-DIP) was used to facilitate communication with subjects. Subjects were encouraged to report symptoms and to call anytime if they felt their resistance to ST usage slipping. Subjects also received a colourful quarterly newsletter updating them on the project's progress, giving new tips on how to stay quit, and stories on individual subject's success stories.

\section{Follow up}

Subjects in the patch groups were called at the following post-intervention times: 2 weeks, 4 weeks, 8 weeks, 3 months, 6 months, 9 months, and 12 months. Each call lasted about 15 minutes and was used to provide stage based 
counselling - that is, students in the maintenance stage received counselling on how to stay quit while students who had relapsed to the active quitting stage received counselling appropriate to that stage. Each time the subject completed a phone counselling, he was mailed a \$5 gift certificate. At the end of one year, if he claimed to be tobaccofree, he was asked to provide a saliva sample for cotinine testing; if he did so, he received a $\$ 50$ gift certificate. Project personnel arranged for a location and time convenient to the subject to receive the saliva sample. Subjects were not told of the gift certificate until after the question about tobacco use was answered, thus preventing any financial incentive to report abstinence.

For patch subjects, tobacco use status was determined at all phone counselling interventions as listed above. For the usual care group, tobacco use status was determined only at two weeks and one year post-intervention.

\section{Medications}

Subjects who were randomised into one of the patch groups were asked to provide a baseline saliva sample which was tested only for cotinine. Those with cotinine values $<150 \mathrm{ng} /$ $\mathrm{ml}$ were considered light to moderate users; those with at least $150 \mathrm{ng} / \mathrm{ml}$ were considered heavy users. Those who showed no cotinine were dropped from the study. Light/ moderate users in the active patch group received the following nicotine patch dosing: $14 \mathrm{mg} \times 3$ weeks followed by $7 \mathrm{mg} \times 3$ weeks. Heavy users' dosages were as follows: $21 \mathrm{mg} \times 2$ weeks, $14 \mathrm{mg} \times 2$ weeks, and $7 \mathrm{mg} \times 2$ weeks.

\section{Measures of outcomes}

This study used an "intention to treat" model. Attrition was most prevalent in the usual care group. At baseline some of the usual care subjects refused to participate further because they wanted to receive the patch, while others did not return the informed consent forms. Of the 105 randomised to the usual care group, only 55 (52\%) remained in the study for one year. The retention rate for active patch users was $66 \%$ $(65 / 98)$ and for placebo patch users, 65\% (65/100).

The main outcome variable was the 30 day point prevalence rates of abstinence for all tobacco and for ST use alone at one year follow up. Subjects were considered to be abstinent if they claimed to be abstinent and had no cotinine in their saliva samples. Data were collected by the health educators and analysed by the project statistician and principal investigator.

\section{Statistical analysis}

Following the "intention to treat" model, all subjects who did not provide information at any time point were considered relapsers for that data collection period. Based on power calculations, each arm needed 75 subjects to have $80 \%$ power to detect differences in quit rates between active and placebo patch groups of $48 \%$ and $25 \%$, respectively, at the 0.05 level. The sample sizes of subjects randomised to each arm were increased to allow for attrition.

Categorical characteristics were compared among treatment arms using $\chi^{2}$ tests, and continuous variables were compared with the Kruskall-Wallis test (non-parametric analog of one way analysis of variance (ANOVA)). Exact 95\% confidence intervals for cessation rates were based on the binomial distribution and calculated using StatXact- 4 . Probability values for comparing cessation rates are based on two sided Fisher's exact tests.

\section{RESULTS}

\section{Baseline characteristics of sample}

The baseline characteristics of the study sample are shown in table 1 . There were no significant differences among the
Table 1 Sample baseline demographics

\begin{tabular}{|c|c|c|c|}
\hline & $\begin{array}{l}\text { Usual care } \\
(\mathrm{n}=45)\end{array}$ & $\begin{array}{l}\text { Nicotine patch } \\
(n=60)\end{array}$ & $\begin{array}{l}\text { Placebo patch } \\
(\mathrm{n}=62)\end{array}$ \\
\hline Age (median) & 17 & 17 & 16 \\
\hline Ethnicity (\% white) & 93.3 & 91.4 & 95.2 \\
\hline Grade (\% seniors) & 42.2 & 46.7 & 42.0 \\
\hline Grade point scale* & 4 & 4 & 4 \\
\hline $\begin{array}{l}\text { Mother's education } \\
\text { (\% completing HS) }\end{array}$ & 62.2 & 67.8 & 80.0 \\
\hline $\begin{array}{l}\text { Father's education } \\
\text { (\% completing HS) }\end{array}$ & 66.7 & 63.3 & 72.1 \\
\hline Tobacco use at entry $\dagger$ & & & \\
\hline Snuff (\%) & 80 & 88.3 & 91.9 \\
\hline Chew (\%) & 27.3 & 42.1 & 34.9 \\
\hline Cigarette (\%) & 76.1 & 81.0 & 65.6 \\
\hline \multicolumn{4}{|c|}{$\begin{array}{l}\text { *Grade point scale: } 1-8 \text { with } 1=\text { mostly As and } 8=\text { mostly Fs. } \\
\text { †At baseline all subjects were current users of either snuff or chew } \\
\text { tobacco. } \\
\text { HS, high school. }\end{array}$} \\
\hline
\end{tabular}

groups. Only subjects who returned consent forms were included in this analysis.

\section{Abstinence rates}

Because of the age of the subjects and the difficulty in getting adolescents to take forms home, have them signed, and returned, our procedure for enrolling subjects had to be modified from the standard for randomised clinical trials. When we met with all potential subjects at a high school, we presented a programme on the hazards of ST use and the need for ST cessation followed by a thorough discussion of our study. We then asked anyone who was interested in enrolling in the study to come forward. We randomised them at that time, gave them consent forms to take home, and took their phone numbers to enable us to contact them about the first class. We also met with the "usual care" group separately and provided them the brief (3-5 minute) counselling. This group was asked to mail back their baseline questionnaire along with their signed consent forms; we called them approximately two weeks later to reinforce the counselling. Although the number of usual care subjects who followed through with the informed consent was fairly low, the number of subjects in both patch groups who returned consent forms was essentially the same (approximately 65\%). This low return rate is a characteristic of the adolescent population and is not unique to our study. Following the standards of the intention-to-treat model, all subjects who failed to return their consent forms were considered "failures" in all subsequent analyses.

Questions about level of exposure to tobacco and levels of addiction were included in the baseline questionnaire, but yielded results that could not be analysed because of lack of variation. Almost all of the subjects' cotinine values were in the "light" range-that is, < $150 \mathrm{ng} / \mathrm{dl}$. In addition, essentially none of the subjects reported having the first dip of the day within 30 minutes of waking, a measure found to be correlated to cotinine values. ${ }^{22}$

The 303 potential subjects were randomised into approximately equal groups. Table 2 shows the abstinence rates for the three groups by time point.

This table indicates a natural history of quitting through the data for the usual care group: although they had a very low abstinence rate at the end of the intervention (3.8\%), it increased to $12.4 \%$ at one year even though they received no additional interventions. The ineffectiveness of the nicotine patch is also obvious in this table: immediately after the intervention and even six months later, there were no significant differences in abstinence rates between active and placebo patch users. At one year, both patch groups had 
Table 2 Tobacco use abstinence at baseline, six months, and one year

\begin{tabular}{|c|c|c|c|c|}
\hline & $\begin{array}{l}\text { Usual care } \\
(n=105)\end{array}$ & $\begin{array}{l}\text { Nicotine patch } \\
(n=98)\end{array}$ & $\begin{array}{l}\text { Placebo patch } \\
(n=100)\end{array}$ & $\begin{array}{l}\text { Both patch groups } \\
(n=198)\end{array}$ \\
\hline \multicolumn{5}{|l|}{ Time 0 (post-classes) } \\
\hline & 30.3 \\
\hline Spit tobacco (\%) & N/A $\ddagger$ & 15.3 & 17.0 & 16.2 \\
\hline \multicolumn{5}{|l|}{1 year } \\
\hline Spit tobacco (\%) & 11.4 & 17.3 & 25.0 & 21.2 \\
\hline Snuff (\%) & 12.4 & 18.4 & 26.7 & 22.6 \\
\hline Chew tobacco (\%) & 22.9 & 29.6 & 36.0 & 32.8 \\
\hline Cigarette (\%) & 14.3 & 12.2 & 23.0 & 17.7 \\
\hline All tobacco (\%) & 7.6 & 6.1 & 13.0 & 9.6 \\
\hline \multicolumn{5}{|c|}{$\begin{array}{l}\text { *Spit tobacco = snuff and chew tobacco combined-that is, percentage of subjects who used neither form. } \\
\text { †Time } 0 \text { for usual care is } 2 \text { week follow up; for patch groups, time } 0=\text { end of the } 9 \text { weeks of behavioural and patch } \\
\text { intervention. } \\
\text { fUsual care subjects were not queried about tobacco status at } 6 \text { months. }\end{array}$} \\
\hline
\end{tabular}

significantly higher abstinence rates compared to usual care. Assuming that the active patch made no difference, we combined the two patch groups to determine whether the behavioural intervention was efficacious: the data indicate that the abstinence rates were almost double those of the usual care group (for one year spit tobacco abstinence in combined patch groups $v$ usual care, $\mathrm{p}=0.04$; for placebo $v$ active patch, $\mathrm{p}=0.22$ )

Smoking remained a problem for ST users. Although it is common for ST users to also smoke cigarettes on occasion, our behavioural intervention did not spend much time educating subjects about the hazards of smoking.

\section{Adverse reactions}

There were no serious adverse events among patch users. Minor events included skin irritation (three subjects) and headaches (two subjects). Two of the subjects with skin irritation were able to resolve this problem by rotating the application site, but one subject had to be removed from patch therapy after three weeks because of the hyperreaction. Two subjects who reported headaches were removed from patch therapy within the first week.

\section{DISCUSSION}

Recent studies have reported higher cessation rates among ST users. Walsh et $a^{23}$ reported a $38 \%$ one year point prevalence rate among college athletes who had received a combination intervention. Their intervention included intensive counselling at baseline, follow up counselling, and permission/ encouragement to use other adjuncts such as nicotine gum and patches. Subjects reported that the two most helpful factors in quitting were in seeing photographs of the disfigurement that can be caused by ST use and by having an oral screening that found lesions in subjects' mouths.

However, the use of the nicotine patch as an adjunct in ST addiction treatment has not been demonstrated. Hatsukami et $a l^{24}$ found patches to be helpful in the short term for reducing cravings, but beyond 15 weeks abstinence rates were not significantly different from controls. A study involving minimal contact and the use of nicotine patches among adult ST users found a six month point prevalence abstinence rate was not significantly different from those using placebo patches. Their use of a seven day time frame for defining use makes it more difficult to compare to the 30 day time frame used with adolescents, and would probably result in a reduction of abstinence rates had the 30 day period been used. ${ }^{25}$

From the present study and those cited above, it appears that the nicotine patch does not offer a significant improvement in long term abstinence rates among adolescents addicted to ST. However, intensive group behavioural

\section{What this paper adds}

Before this study, no cessation programmes for adolescent spit tobacco users had yielded abstinence rates higher than $13 \%$ at six months. The prevalence of spit tobacco use among adolescent males is high (35\% in many parts of the country) and has not improved over the past two decades.

This study found that a behavioural intervention based on National Cancer Institute spit tobacco materials can significantly improve spit tobacco cessation rates in this population. It also found that nicotine patches do not enhance cessation rates when used in combination with the standardised intervention. More research needs to be done on the use of newer pharmacologic adjuncts such as bupropion.

interventions do offer significantly higher long term abstinence rates than minimal or no contact interventions. The content for these interventions are available from the National Cancer Institute and the Centers for Disease Control and Prevention and can be used by school nurses or health educators at little or no cost.

Future research should investigate the use of other pharmacologic agents, such as bupropion, and the development of improved behavioural interventions. Attention should also be paid to including content related to smoking cessation.

\section{ACKNOWLEDGEMENTS}

This study was conducted with a grant from the National Cancer Institute, 1 R01 CA76969-03. The authors wish to express appreciation to Carol VanPelt, Ashlee Bradley, Cara Atkinson, and Charlie Stutts for their help in working on the project and collecting and entering the data.

\section{Authors' affiliations}

R C Stotts, University of Tennessee Health Science Center, Memphis, Tennessee, USA

P K Roberson, E Y Hanna, S K Jones, C K Smith, University of Arkansas for Medical Sciences, Little Rock, Arkansas, USA

\section{REFERENCES}

1 Kann L, Kinchen SA, Williams BI, et al. Youth risk behavior surveillance United States, 1999. CDC surveillance summaries June 9, 2000. MMWR Morb Mortal Wkly Rep 2000;49(SS-5): 1-95.

2 Substance Abuse and Mental Health Services Administration. National household survey on drug abuse: population estimates 2000. Office of Applied Studies, USDHHS, 2000.

3 Gottlieb A, Pope SK, Rickert VI, et al. Patterns of smokeless tobacco use by young adolescents. Pediatrics 1993;91:75-8. 
4 Healton C, Messeri P, Reynolds J, et al. Tobacco use among middle and high school students - United States, 1999. MMWR Morb Mortal Wkly Rep 2000;49:49-53.

5 Winn DM. Tobacco use and oral disease. J Dental Educ 2001;65:306-12.

6 Blot WJ, McLaughlin JK, Winn DM, et al. Smoking and drinking in relation to oral and pharyngeal cancer. Cancer Res 1988;48:3282-7.

7 Winn DM, Blot WJ, Shy CM, et al. Snuff dipping and oral cancer among women in the southern United States. N EnglJ Med 1981;304:745-9.

8 Ernster VL, Grady DG, Greene JC, et al. Smokeless tobacco use and health effects among baseball players. JAMA 1990;264:218-24.

9 Novello AC. Foreward in: Smokeless tobacco or health: an international perspective. Bethesda, Maryland: NIH. National Cancer Institute, 1993:ix-xv. (DHHS publication NIH 93-3461).

10 Westman EC. Does smokeless tobacco cause hypertension? Southern Med J 1995;88:716-20.

11 Hatsukami DK, Severson HH. Oral spit tobacco: addiction, prevention and treatment. Nicotine \& Tobacco Research 1999;1:21-44.

12 Haddock CK, Weg MV, DeBon M, et al. Evidence that smokeless tobacco use is a gateway for smoking initiation in young adult males. Prev Med 2001;32:262-7.

13 Centers for Disease Control and Prevention. Youth tobacco surveillanceUnited States, 1998-1999. MMWR Morb Mortal Wkly Rep CDC Surveillance Summaries 2000:49:13.

14 Severson H. Enough snuff: ST cessation from the behavioral, clinical, and public health perspectives. In: Smokeless tobacco or health: an international perspective. Bethesda, Maryland: N.I.H. National Cancer Instutute, 1993:279-290. (DHHS publication NIH 93-3461.)

15 Glover ED. Conducting smokeless tobacco cessation clinics [letter]. Am J Public Health 1986;76:207.
16 Eakin E, Severson HH, Glasgow RE. Development and evaluation of a smokeless tobacco cessation program: a pilot study. $\mathrm{NCl}$ Monographs 1989;8:95-100.

17 Schinke SP, Gilchrist LD, Schilling RF, et al. Smoking and smokeless tobacco use among adolescents: Trends and intervention results. Public Health Reports 1986;101:373-8.

18 Stevens VJ, Severson HH, Lichtenstein E, et al. Making the most of a teachable moment: a smokeless-tobacco cessation intervention in the dental office. Am J Public Health 1995;85:231-5.

19 Boyle RG, Stilwell J, Vidlak LM, et al. "Ready to quit chew?" Smokeless tobacco cessation in rural Nebraska. Addictive Behaviors 1999;24:293-7.

20 Smith TA, House RF, Croghan IT, et al. Nicotine patch therapy in adolescent smokers. Pediatrics 1996;98:659-67.

21 Hatsukami D, Jensen J, Allen S, et al. Effects of behavioral and pharmacological treatment on smokeless tobacco users. J Consult Clin Psychol 1996;64:153-61

22 Boyle RG, Jensen J, Hatsukami DK, et al. Measuring dependence in smokeless tobacco users. Addictive Behaviors 1995;20:443-50.

23 Walsh MM, Hilton JF, Masouredis CM, et al. Smokeless tobacco cessation intervention for college athletes: results after 1 year. Am J Public Health 1999;89:228-34.

24 Hatsukami DK, Grillo M, Boyle R, et al. Treatment of spit tobacco users with transdermal nicotine system and mint snuff. J Consult Clin Psychol 2000;68:241-9.

25 Howard-Pitney B, Killen JD, Fortmann SP. Quitting chew: results from a randomized trial using nicotine patches. Exp Clin Psychopharmacol 1999;7:362-71. 